Original research article

\title{
The NF- $\kappa$ B pathway is critically implicated in the oncogenic phenotype of human osteosarcoma cells
}

\author{
Bingyi Tan, Zenong Yuan, Qingyu Zhang, Xu Xiqiang, Jun Dong* \\ Shandong First Medical University, Shandong Provincial Hospital, Department of Orthopaedics, Jinan City, China
}

\section{Abstract}

NF- $k B$ is activated in a variety of human cancers. However, its role in osteosarcoma (OS) remains unknown. Here, we have elucidated the implication of NF- $\mathrm{BB}$ in the oncogenic phenotype of OS tumor cells. We reported that activation of NF- $\mathrm{BB}$ was a common event in the human OS. Inhibition of NF- $\mathrm{BB}$ using inhibitor Bay 11-7085 repressed proliferation, survival, migration, and invasion but increased apoptosis in 143B and MG63 OS cells, indicating that NF- $\mathrm{BB}$ is critically implicated in the oncogenesis of OS. Notably, Bay 11-7085 not only inactivated NF- $\mathrm{KB}$ but also reduced the phosphorylation of AKT via its induction of PTEN, suggesting the existence of a novel $\mathrm{NF}-\kappa \mathrm{B} / \mathrm{PTEN} / \mathrm{PI} \mathrm{KK} / \mathrm{AKT}$ axis. In vivo, Bay 11-7085 suppressed tumor growth in the bone by targeting NF- $\mathrm{kB}$ and AKT. Interestingly, combined treatment with Bay 11-7085 and the PI3K inhibitor, LY294002, triggered an augmented antitumor effect. Our results demonstrate that NF- $\kappa$ B potentiates the growth and aggressiveness of OS. Pharmacological inhibition of NF- $\kappa$ B represents a promising therapy for the treatment of OS.
\end{abstract}

Keywords: AKT; NF-кB; Osteosarcoma; Treatment

\section{Highlights:}

- Activation of NF- $\kappa$ B pathway is a common event in the human OS cells, which is critically implicated in the pathogenesis of OS.

- NF- $\mathrm{BB}$ potentiates tumor growth and aggressiveness via its crosstalk with PI3K/AKT pathway, thus forming a novel NF- $\kappa$ B/PTEN/PI3K/AKT signaling axis.

- Pharmacological inhibition of NF- $\mathrm{KB}$ using its inhibitor is effective to suppress tumor growth and represents a therapeutic potential against OS.

- Combination treatment using inhibitors targeting multiple oncogenic pathways simultaneously may enhance the response to therapy and also reduces the chances of toxicity.

\section{Introduction}

In children and adolescents, osteosarcoma (OS) is the most common primary malignant bone tumor that mainly affects long bones. Although the histopathology of this bone cancer is well studied, the molecular mechanism underlying OS tumorigenesis and progression remains poorly understood. Achieving an in-depth understanding of the signaling pathways that regulate osteosarcomagenesis may aid in developing personalized targeted therapeutics to increase patient survival.

In the pathogenesis of human OS, the most critical pathways involved are Notch, Wnt, NF- $\mathrm{B}, \mathrm{p} 53, \mathrm{PI} \mathrm{K} / \mathrm{AKT}$, and MAPK (Kushlinskii et al., 2016). NF- $\kappa B$ belongs to a family of transcriptional factors that include p50, p52, p65 (RelA), RelB, and c-Rel (Vallabhapurapu and Karin, 2009). NF-kB is normally kept inactive in the cytoplasm through interaction

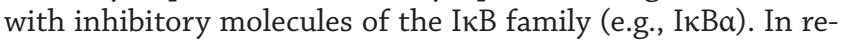

sponse to multiple stimuli, such as growth factors, cytokines, viral or bacterial products, or various types of stress, the I $\mathrm{B}$ molecules become phosphorylated on the two critical serine residues (Ser32 and Ser36). This modification marks it for degradation through proteasome-mediated ubiquitination (Israel, 2010). As a result, NF- $\kappa B$ is released and enters the nucleus, where it initiates the transcription of target genes.

$\mathrm{NF}-\kappa \mathrm{B}$ has a key function in regulating the human immune system, and its dysregulation has been linked to many chronic diseases, such as asthma, diabetes, rheumatoid arthritis, inflammation, and cancer (Kunnumakkara et al., 2020). Hyperactivity of NF-kB has been shown in several types of cancer and is known to control the expression of a plethora of genes that promote tumor cell proliferation, survival, metastasis, invasion, and angiogenesis. Despite some evidence indicating that NF- $\mathrm{KB}$ may also function as a tumor suppressor, this transcription factor has been identified to be a major contributor to cancer initiation and development (Puar et al., 2018). In OS,

\footnotetext{
* Corresponding author: Jun Dong, MD, PhD, Department of Orthopaedics, Shangdong Provincial Hospital, No. 324, the Five Weft Seven Road, Jinan City, Shandong Province, 250021, P.R. China; e-mail: jundongortho@yahoo.com http://doi.org/10.32725/jab.2021.021 
NF- $\kappa \mathrm{B}$ is expressed in $75.3 \%$ and $32.9 \%$ in tumor specimens and adjacent non-tumor tissues, respectively, suggesting that NF- $\kappa B$ is upregulated in this bone cancer (Gong et al., 2017).

TMIGD3 isoform1 acts as an inhibitor of NF- $\mathrm{B}$, knockdown of which increases OS cell proliferation and tumor formation (Iyer et al., 2016). Caffeine can induce the pro-apoptotic activity of OS cells via its inhibition of multiple pathways, including NF- $\mathrm{B}$ (Miwa et al., 2012). Aspirin also diminishes OS cell motility and metastasis by targeting NF- $\kappa B$ (Liao et al., 2015). Notably, Tang et al. (2012) reported that inhibition of GSK-3 $\beta$ suppresses NF- $\kappa B$ transcriptional activity and subsequently results in the induction of apoptosis in OS cells, suggesting that GSK-3 $\beta$ stimulates tumor cell survival via its downstream NF-kB.

Although these studies imply that NF- $\kappa$ B plays a role in osteosarcomagenesis, the mechanism by which $\mathrm{NF}-\kappa \mathrm{B}$ regulates OS oncogenesis remains largely unknown. As such, it is imperative to achieve an in-depth understanding regarding the modulation of NF- $\mathrm{KB}$ in this bone cancer. It is also important to address whether pharmacological inhibition of NF- $\kappa$ B can function as an efficient therapeutic approach for the treatment of OS.

$\mathrm{PIBK} / \mathrm{AKT}$ is a central intracellular pathway that is frequently activated in diverse human cancers, including OS (Gorlick et al., 2012; Liu et al., 2020; Xi and Chen, 2017). PI3K phosphorylates $\mathrm{PIP}_{2}$ to $\mathrm{PIP}_{3}$, and this leads to the activation of AKT kinase (Georgescu, 2010). Activation of AKT phosphorylates a variety of substrates that regulate cell proliferation, viability, apoptosis, motility, and differentiation (Polivka and Janku, 2014). Of note, the crosstalk between PI3K/AKT and $\mathrm{NF}-\kappa \mathrm{B}$ has been documented in human diseases. Activation of the PI3K/AKT/NF- $\kappa \mathrm{B}$ signaling axis is involved in the development of acute lung injury (Jin et al., 2017) and the anti-inflammatory effect of IB-MECA in arthritis (Fishman et al., 2006). This pathway nexus is also implicated in human cancers, such as ovarian and esophageal cancer (Ghoneum and Said, 2019; $\mathrm{Li}$ et al., 2007). Interestingly, the PI3K/AKT/NF- $\mathrm{KB}$ signaling cascade has been identified in OS. For instance, CXCR4 activates PI3K/AKT and exerts anti-apoptotic activity of human OS cells via NF- $\kappa B$ (Jiang et al., 2018). MARK2 also improves the resistance of OS cells to cisplatin chemotherapy by activating the PI3K/ AKT/NF- $\mathrm{kB}$ axis (Wei et al., 2020).

As NF- $\kappa B$ can act as a substrate of AKT kinase, it is not surprising that NF- $\kappa \mathrm{B}$ activation occurs downstream of PI3K/ AKT. However, a previous study has reported that NF- $\kappa B$ could repress PTEN expression and prevent apoptosis in a subset of lung and thyroid cancers (Vasudevan et al., 2004). Since PTEN is so far the only lipid phosphatase that antagonizes the PI3K/ AKT signaling pathway by converting $\mathrm{PIP}_{3}$ to $\mathrm{PIP}_{2}$, whether NF- $\kappa B$ could also regulate PI3K/AKT activity via its inhibition of PTEN (that is, an NF- $\mathrm{KB} / \mathrm{PTEN} / \mathrm{PI3K} / \mathrm{AKT}$ signaling cascade) in human OS cells warrants investigation.

In this study, we explored the modulating effect of $N F-\kappa B$ in the oncogenic phenotype of human OS cells, and also investigated the interaction between $\mathrm{NF}-\kappa \mathrm{B}$ and the PTEN/PI3K/AKT signaling pathway. We hypothesized that pharmacological inhibition of NF- $\mathrm{KB}$ could repress tumor growth and aggressiveness, while combination treatment using inhibitors targeting both NF- $\mathrm{KB}$ and PI3K/AKT would trigger an additive or synergistic antitumor effect in OS cells.

\section{Materials and methods}

\section{Cell culture}

Three human OS cell lines, including U2OS, MG63, 143B, as well as human normal osteoblast cell line FOB, were purchased from ATCC. All cells were cultured in the growth medium, which contains Dulbecco's Modified Eagle's Medium (DMEM, Invitrogen) and $10 \%$ fetal bovine serum (FBS, Invitrogen), in an incubator at $37{ }^{\circ} \mathrm{C}$ with $5 \% \mathrm{CO}_{2}$. The cells were treated with Bay 11-7085 (an NF- $\mathrm{kB}$ inhibitor, Sigma-Aldrich) at various dosages dissolved in DMSO. The control cells were treated with the same volume of DMSO only.

\section{Proliferation, motility, and survival assay}

Cell proliferation rate was evaluated with the MTT proliferation kit (Cayman Chemical) using the protocol provided by the manufacture. Absorbance at $570 \mathrm{~nm}$ was determined. The assay was conducted for 5 days. The migration of cells was assessed using a scratch healing approach (Liang et al., 2007). The width of the healing gap was measured using the ImageJ software. The invasion of cells was evaluated using the Boyden chambers system with filter inserts pre-coated with Matrigel, as was previously reported (Ritch et al., 2019). Uninvaded cells were eliminated with cotton swabs. Inserts were stained with $0.9 \%$ crystal violet. Cells were also cultured under serum starvation conditions (DMEM-0.5\% FBS) for $48 \mathrm{~h}$. The viability was assessed using a Luminescent Assay Kit (Promega). The apoptosis was examined by measuring the caspase 3 activity using a Caspase-3 Assay Kit (Abcam).

\section{NF- $\kappa$ B reporter assay}

The NF- $\kappa$ B reporter activity was evaluated with the NF- $\kappa$ B Reporter Kit (BPS Bioscience). Briefly, the NF-kB-responsive firefly luciferase reporter plasmid and a renilla luciferase plasmid were co-transfected into tumor cells using the Lipofectamine 2000 reagent (Invitrogen). After $24 \mathrm{~h}$, the basal level of the $\mathrm{NF}-\kappa \mathrm{B}$ reporter activity was determined by the Dual-Luciferase Reporter Assay Kit (Promega). The same reporter assay was also conducted in tumor cells that had been treated with Bay 11-7085 (10 $\mu \mathrm{M})$, and/or TNFa (20 ng/ml, R\&D) for $24 \mathrm{~h}$.

\section{Real-time quantitative PCR (qPCR) and Western blot}

Total RNA was extracted from tumor cells using the Qiagen RNeasy Kit (Qiagen). RNA was then reverse transcribed to cDNA with the qScript SuperMix (Quanta Biosciences). qPCR was conducted using SYBR Green Master Mix. The primers for qPCR are listed in Table 1. PCR products were analyzed with the 7900HT Detection System (Applied Biosystems). The relative mRNA expression level of target genes was analyzed using the RQ Manager (Applied Biosystems). For Western blot, cell lysates were isolated with the RIPA buffer (Sigma-Aldrich). The protein samples were separated using $10 \%$ SDS polyacrylamide gel electrophoresis (SDS-PAGE) and were then transferred onto a PVDF membrane (Millipore). After washing with TBST, the membrane was blocked with $1 \%$ BSA and incubated with primary antibodies (Table 2) at $4{ }^{\circ} \mathrm{C}$ overnight. The membrane was then incubated with horseradish peroxidase-conjugated secondary antibodies (Bio-Rad) for $45 \mathrm{~min}$. The protein bands were detected using the ECL detection reagents (Thermo Fisher). 
Table 1. PCR primers

\begin{tabular}{lll}
\hline Genes & Forward (5'-3') & Reverse (5'-3') \\
\hline BAFF & CACAATTCAAAGGGGCAGTAA & ACTGAAAAGGAGGGAGTGCAT \\
IFN- $\gamma$ & TGAACGCTACACACTGCATCTTGG & CGACTCCTTTTCCGCTTCCTGAG \\
IL-6 & GGTACATCCTCGACGGCATCT & GT GCCTCTTTGCTGCTTTCAC \\
IL-8 & AAGAGAGCTCTGTCTGGACC & GATATTCTCTTGGCCCTTGG \\
TRAF-1 & GCCACCTCTATCCACCAGA & CTGGCCACGTTGGTTTCAC \\
PTEN & AAGACAAAGCCAACCGATAC & GAAGTTGAACTGCTAGCCTC \\
GAPDH & CCTCTATGCCAACACAGTGC & GTACTCCTGCTTGCTGATCC \\
\hline
\end{tabular}

Table 2. Antibody list

\begin{tabular}{|c|c|c|c|}
\hline Antibodies & Manufactures & Cat No. & Use \\
\hline Phospho-IкBa (Ser32/36) & Cell Signaling & 9246 & WB \\
\hline $\mathrm{I \kappa} B a$ & Cell Signaling & 9242 & WB \\
\hline Phospho-NF-кB p65 (Ser536) & Cell Signaling & 3033 & WB \\
\hline NF-kB p65 & Cell Signaling & 6956 & WB, IHC \\
\hline Phospho-Akt (Ser473) & Cell Signaling & 4060 & WB, IHC \\
\hline Akt & Cell Signaling & 9272 & WB \\
\hline$\beta$-actin & Abcam & ab8227 & WB \\
\hline Anti Mouse IgG & Cell Signaling & 7076 & WB \\
\hline Anti Rabbit IgG & Cell Signaling & 7074 & WB \\
\hline
\end{tabular}

\section{Intratibial xenograft mouse model}

Before injection, 143B cells were collected and resuspended in a PBS/Matrigel mixture $(1: 1)$ at a density of $2 \times 10^{7} / \mathrm{ml}$. A total of 16 male 6 8-week-old NOD/SCID mice were used in the study. Anesthesia was performed by intraperitoneal injection of a ketamine $(80 \mathrm{mg} / \mathrm{kg}) /$ xylazine $(10 \mathrm{mg} / \mathrm{kg})$ cocktail. $2 \times 10^{5}$ cells in $10 \mu \mathrm{l}$ volume were injected into the bone marrow cavity using a microsyringe (Hamilton). After the operation, mice received an intraperitoneal injection of Bay 11-7085 (10 mg/kg) or DMSO as a control $(n=8)$ immediately and twice a week. After 3 weeks, mice were radiographically examined using a Faxitron MX-20 X-ray machine.

\section{Histology and immunohistochemistry (IHC)}

Animals were sacrificed at 3 weeks post-operation. The affected legs were fixed with 4\% PFA for 2 days and decalcified with $20 \%$ EDTA for 7 days. Samples were embedded in paraffin. Sections with 7- $\mu \mathrm{m}$ thickness were treated with routine hematoxylin-eosin (HE) staining. Other tumor sections were incubated in a $90{ }^{\circ} \mathrm{C}$ water bath in a pressure cooker for $10 \mathrm{~min}$ for antigen retrieval. The sections were incubated with a primary antibody against phosphorylated NF-kB p65 (or phosphorylated AKT) overnight at $4{ }^{\circ} \mathrm{C}$ (Table 2), followed by the incubation with a biotinylated secondary antibody. The immunoreactive signals were developed using the DAB substrate (Vector Lab).

\section{Statistical analyses}

All statistical analyses were conducted using the GraphPad Prism software. The two-tailed paired Student's $t$-test was used for the comparison between two groups and one-way ANOVA was used for the comparison among multiple groups. Experiments were performed in triplicate. Data are reported as mean $\pm \mathrm{SD}$. The $p$-value of less than 0.05 was considered statistically significant.

\section{Results}

\section{The NF- $\kappa B$ pathway is activated in human OS cells}

To uncover the critical involvement of NF- $\mathrm{KB}$ in OS, we first investigated the phosphorylation of the NF- $\mathrm{kB}$ p65 subunit. We found that all three OS cell lines tested, including U2OS, MG63, and 143B cells, exhibited a higher level of phosphorylated p65 than that of normal FOB osteoblasts (Fig. 1A). Using an NF- $\mathrm{kB}$ reporter assay, we showed that the baseline luciferase activity was higher in all three tumor cell lines than in FOB osteoblasts (Fig. 1B). These findings suggest that NF$\kappa \mathrm{B}$ is activated in tumor cells, which is a common event in the human OS. Regarding the mechanism underlying NF- $\mathrm{kB}$ activation, we examined the phosphorylation level of IкBa. This is because NF- $\mathrm{KB}$ is negatively regulated by its cytoplasmic

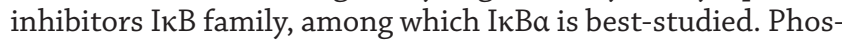
phorylation of IкBa at its Ser32 and Ser36 residues leads to its degradation and thus to the release of NF- $\mathrm{KB}$ (Oeckinghaus and Ghosh, 2009). Here, we observed that the expression of phosphorylated IKBa ${ }^{\mathrm{Ser} 32 / 36}$ was increased in all three tumor cells as compared to FOB cells (Fig. 1B), suggesting that NF- $\kappa B$ is activated via the inhibition of IKBa.

\section{Bay 11-7085 represses proliferation and survival of tumor cells}

Given that NF- $\kappa \mathrm{B}$ was activated in OS cells, our next goal was to explore whether pharmacological suppression of the NF-kB pathway could impact tumor cell behavior. For this reason, we treated OS cells with Bay 11-7085, an irreversible inhibitor of $\mathrm{NF}-\kappa \mathrm{B}$. Using reporter activity assay, we found that this inhibitor reduced the basal level of NF- $\mathrm{kB}$ reporter activity by $68 \%$ and $57 \%$ in $143 \mathrm{~B}$ and MG63 cells, respectively. Notably, 
A

(i)

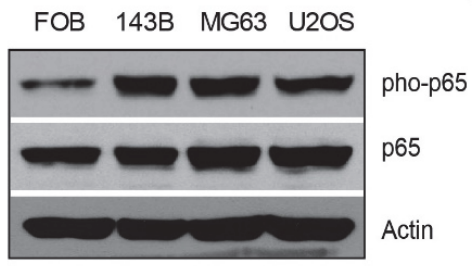

(ii)

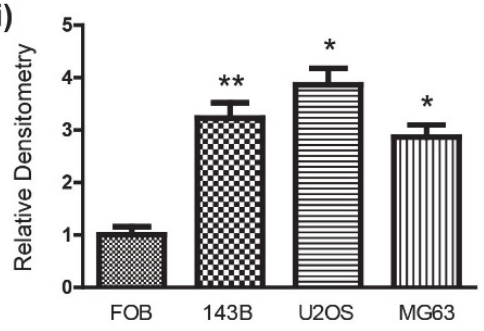

B

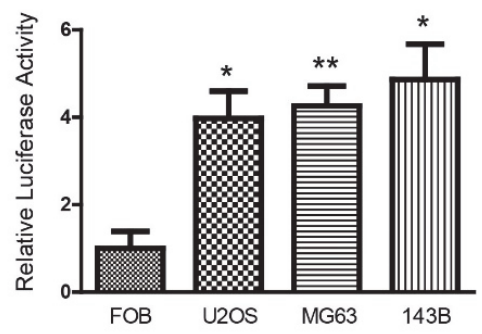

C

(i)

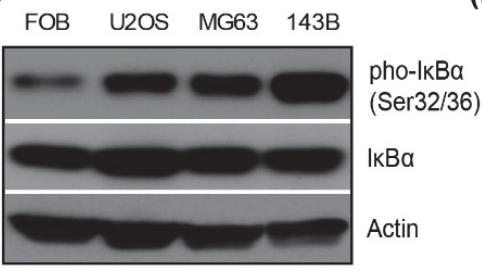

(ii)

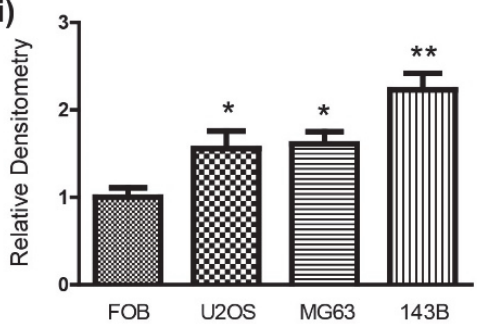

Fig. 1. NF- $\kappa B$ is activated in human OS cells. (A) Western blotting for the expression of phosphorylated p65 (pho-p65) and total p65 in FOB osteoblasts and OS cells (i); the densitometry for the protein bands was analyzed using ImageJ. The ratio of pho-p65/total p65 protein bands was normalized to the $\beta$-actin protein bands. (B) NF- $\kappa$ B reporter activity assay. (C) Western blotting for the expression of phosphorylated

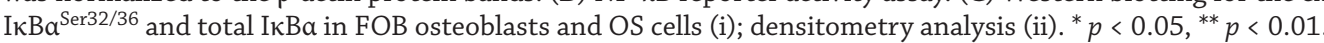

treatment with TNFa, a potent inducer of NF- $\kappa$ B (Hayden and Ghosh, 2014), strongly induced luciferase activity in both cell lines. However, this induction effect was substantially repressed by Bay 11-7085 (Fig. 2A). This inhibitor also decreased the mRNA level of NF- $\mathrm{kB}$ transcription target genes, including BAFF, IL-6, IL-8, and TRAF-1 (Fig. 2B). These results indicate that Bay 11-7085 inactivates NF- $\mathrm{B}$ signaling activity. Further, we showed that treatment with Bay 11-7085 suppressed the proliferation rate of 143B and MG63 tumor cells (Fig. 2C). Bay 11-7085 also inhibited survival in both cell lines, as indicated by reduced cell viability (Fig. 2D) and induced pro-apoptotic activity (Fig. 2E). These results assays suggest that pharmacological inhibition of NF-kB represses OS cell growth and survival.

\section{Bay 11-7085 inhibits migration and invasion of tumor cells}

During cancer aggression (e.g., metastasis), tumor cell migration and invasion are two key steps (Bravo-Cordero et al., 2012; Tahtamouni et al., 2019). We then analyzed the migrative capacity of OS cells using a wound-healing approach. After $48 \mathrm{~h}$, we observed that the gaps were almost healed in OS cells treated with DMSO. In contrast, Bay 11-7085 markedly suppressed the migration process in these cells (Fig. 3A). Further, we evaluated OS cell invasion using a transwell chamber assay and noticed that Bay 11-7085 substantially decreased the number of invaded tumor cells (Fig. 3B). These data show that pharmacological inhibition of NF- $\mathrm{kB}$ inhibits OS cell aggressiveness.

\section{Existence of an NF- $\kappa B / P T E N / P I 3 K / A K T$ signaling axis in tumor cells}

In literature, NF- $\mathrm{BB}$ is shown to be regulated downstream of the PI3K/AKT pathway, thus forming a PI3K/AKT/NF- $\kappa \mathrm{B}$ axis in several human cancers including OS (Jiang et al., 2018; Wei et al., 2020). Strikingly, we found here that treatment with Bay 11-7085 de-phosphorylated AKT in 143B cells (Fig. 4A), suggesting that NF- $\kappa \mathrm{B}$ also functions upstream of PI3K/AKT. Interestingly, we noticed that this inhibitor also upregulated the tumor suppressor PTEN at both protein and mRNA levels (Fig. 4A, B). Since PTEN can counteract PI3K/AKT by de-phosphorylating $\mathrm{PIP}_{3}$ to $\mathrm{PIP}_{2}$ (Papa and Pandolfi, 2019), NF- $\kappa B$ may activate PI3K/AKT via its inhibition of PTEN. To further confirm this causal relationship, we treated 143B tumor cells with Bay 11-7085 with/without VO-OHpic (Tocris), a potent specific PTEN inhibitor. As anticipated, Bay 11-7085 reduced the expression of phosphorylated AKT. Importantly, this reduction was greatly attenuated in cells co-treated with both Bay-117085 and VO-OHpic (Fig. 4C), thus confirming that NF- $\kappa$ B activates AKT by inhibiting PTEN. Hence, it seems highly plausible that a novel NF- $\mathrm{BB} / \mathrm{PTEN} / \mathrm{PI} 3 \mathrm{~K} / \mathrm{AKT}$ signaling axis exists in human OS cells. 

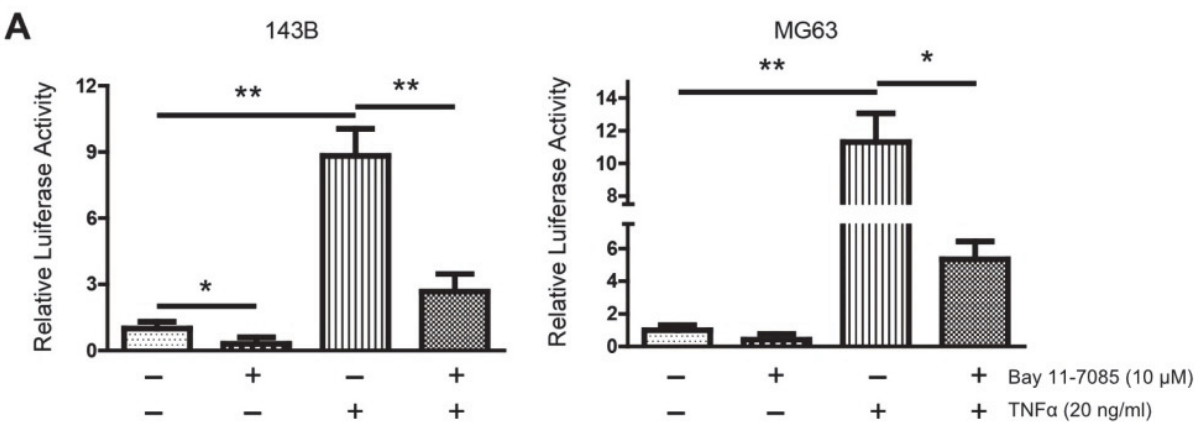

B

143B

MG63
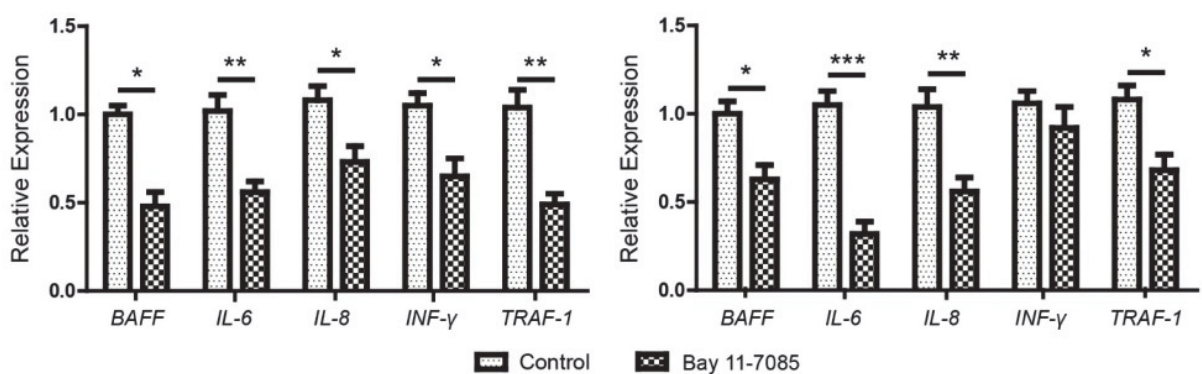

C

143B

MG63
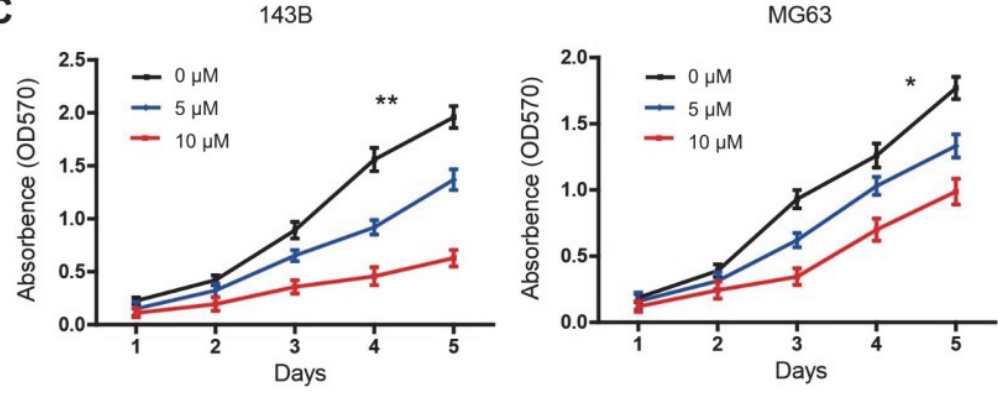

D
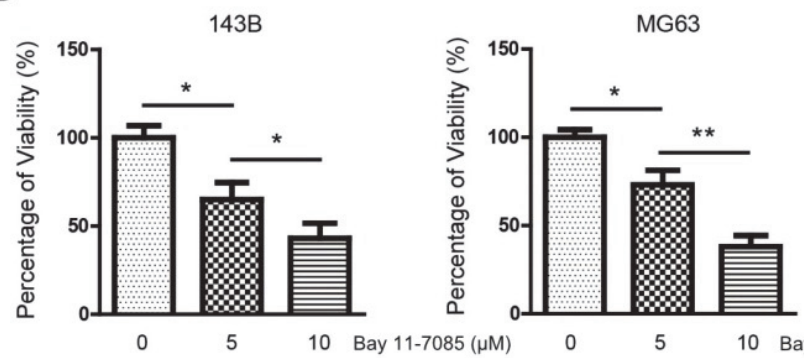

E
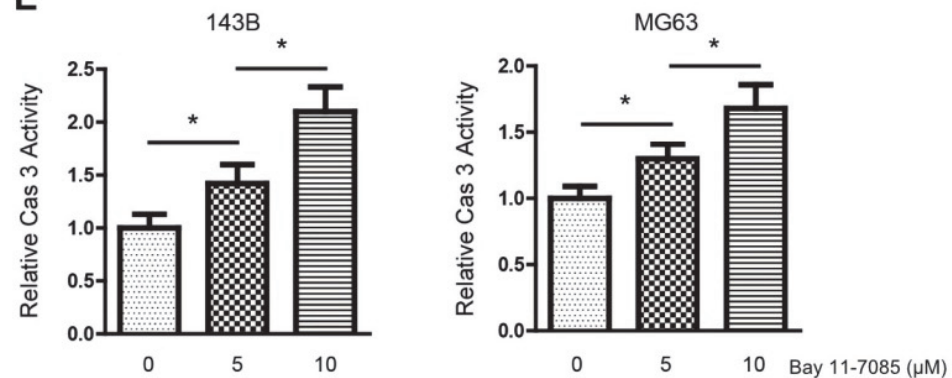

Fig. 2. Bay 11-7085 represses growth and survival of tumor cells. (A) NF-kB reporter assay in tumor cells treated with Bay 11-7085 and/or $\mathrm{TNF} \alpha$ for $24 \mathrm{~h}$. (B) The expression of NF-kB target genes was determined using qPCR in tumor cells treated with Bay 11-7085 (10 $\mu \mathrm{M})$ for $24 \mathrm{~h}$. (C) MTT assay for proliferation rate in tumor cells treated with Bay 11-7085. ** refers to the p-value for the comparison among all 3 groups. Tumor cells were cultured in serum-starved medium and treated with Bay 11-7085 for $48 \mathrm{~h}$, and were examined for the viability (D) and caspase 3 activity $(\mathbf{E})(n=3)$, respectively. ${ }^{*} p<0.05,{ }^{* *} p<0.01,{ }^{* * *} p<0.001$. 
A
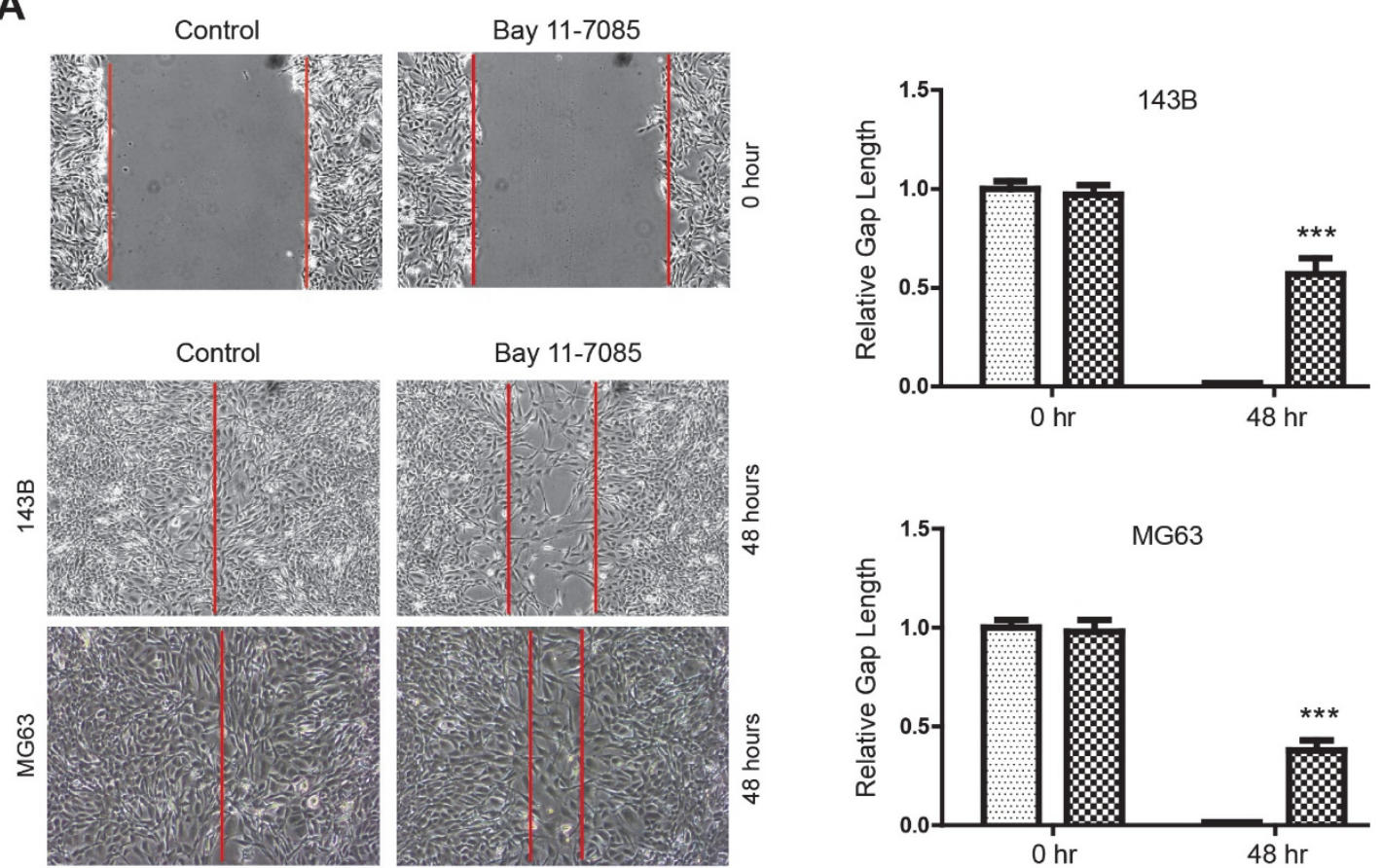

Control

Bay 11-7085

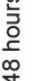

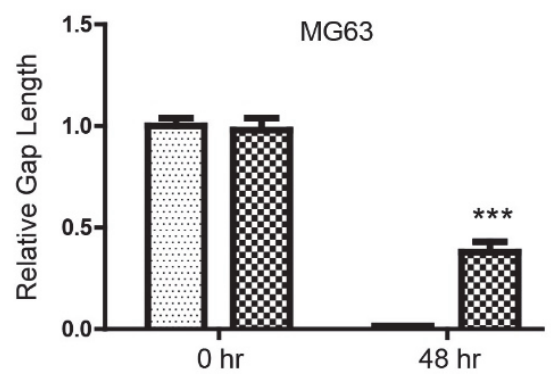

Control

Bay 11-7085

B
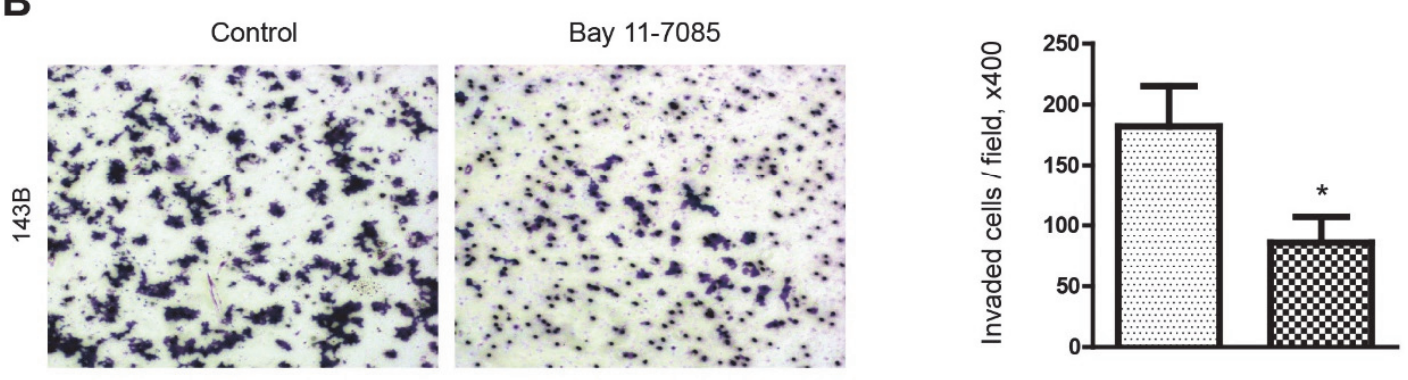

Bay 11-7085
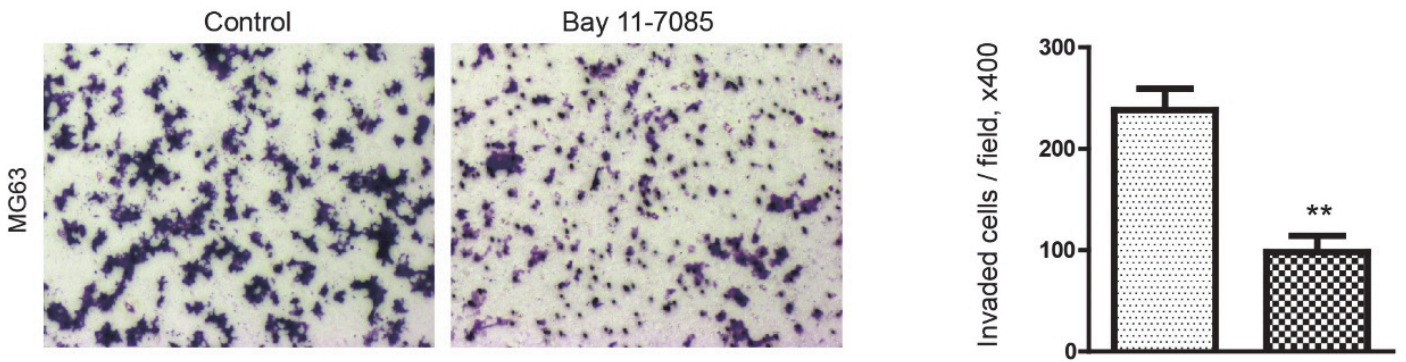

Fig. 3. Bay 11-7085 inhibits migration and invasion of tumor cells. (A) Tumor cells were treated with Bay 11-7085 (10 $\mu \mathrm{M})$ for $48 \mathrm{~h}$, a woundhealing approach was used to determine tumor cell migration. (B) Tumor cells were treated with Bay 11-7085 (10 $\mu \mathrm{M})$ for $24 \mathrm{~h}$, followed by invasion assay. Invaded cells were counted under microscopy. ${ }^{*} p<0.05,{ }^{* *} p<0.01,{ }^{* * *} p<0.001$. 

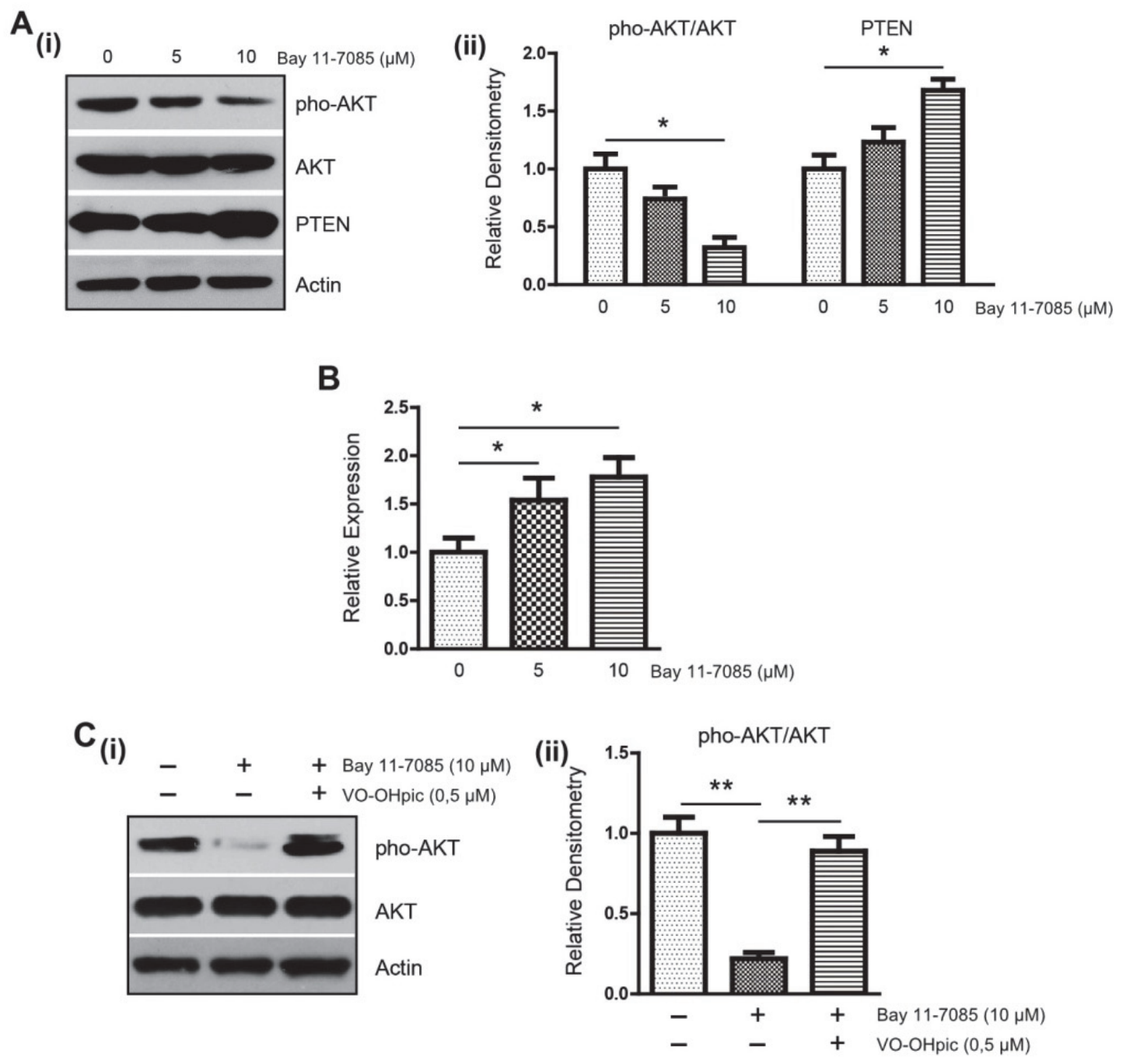

Fig. 4. The presence of an NF-kB/PTEN/PI3K/AKT axis. (A) Treatment with Bay 11-7085 in $143 \mathrm{~B}$ cells for 24 h reduced the phosphorylation of AKT but induced the expression of PTEN using Western blotting (i); densitometry analysis (ii). (B) qPCR assay for PTEN mRNA in 143B cells. (C) Western blotting for the phosphorylated and total AKT in 143B cells treated with Bay 11-7085 and VO-OHpic for $24 \mathrm{~h}$. ${ }^{*} p<0.05,{ }^{* *} p<0.01$. 
A

(i)

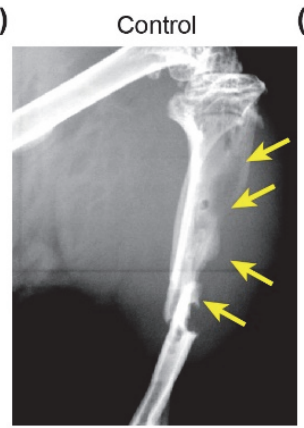

(ii)

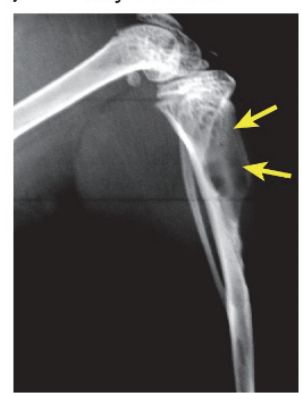

B
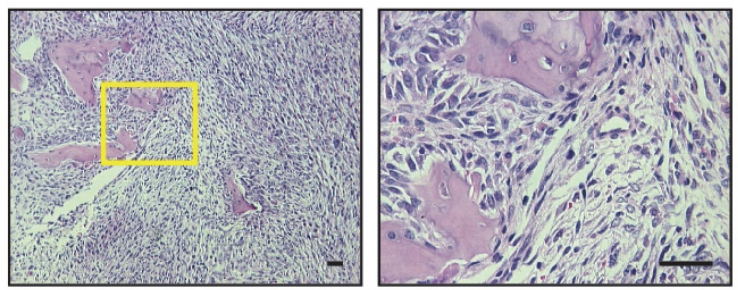

C.

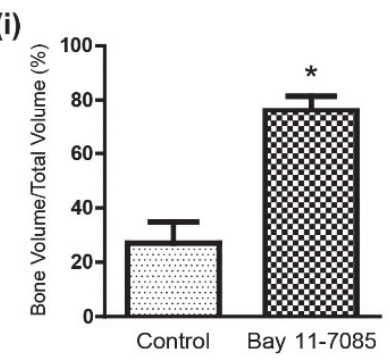

(ii)

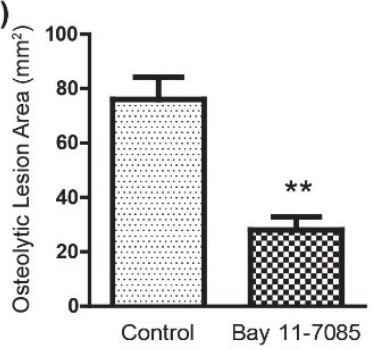

D
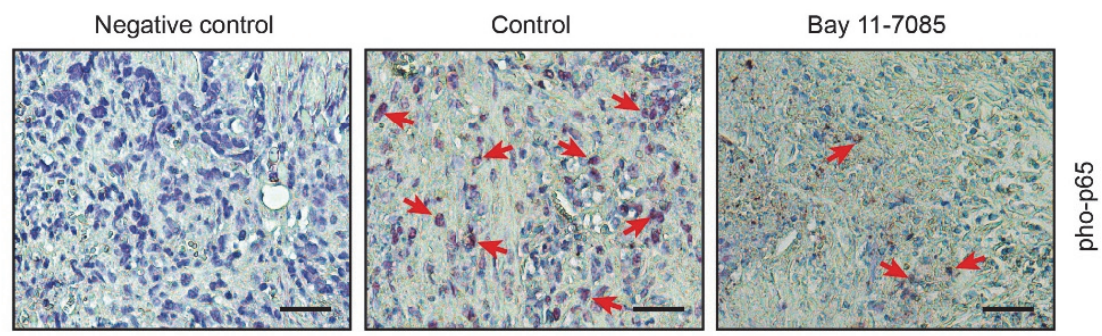

$\mathbf{E}$

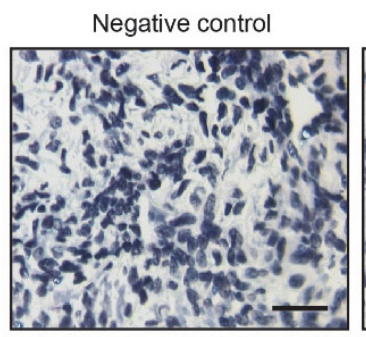

Control

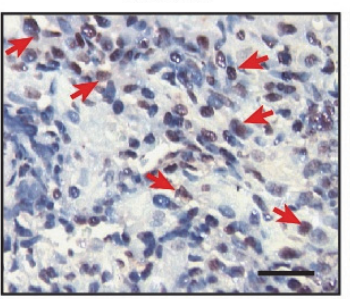

Bay 11-7085

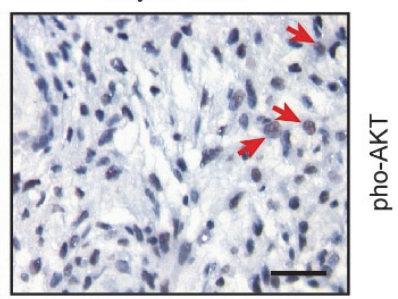

Fig. 5. Bay 11-7085 represses intraosseous tumor growth. (A) X-day radiography showed that Bay 11-7085 inhibited osteolytic bone destructions at 3 weeks post-injection. (B) HE staining on tumor sections. (C) Tumor burden was evaluated using histomorphometry. IHC showed that the expression of pho-p65 (D) and pho-AKT $(\mathbf{E})$ was decreased tumors from Bay 11-7085-treated mice. Scale bar $=100 \mu \mathrm{m}$. ${ }^{*} p<0.05,{ }^{* *} p<0.01$.

\section{Pharmacological inhibition of NF- $\kappa$ B suppresses in vivo tumor growth}

To investigate whether pharmacological inhibition of NF- $\kappa B$ could inhibit in vivo tumor growth, we injected 143B tumor cells into the tibia of NOD/SCID mice and treated animals with Bay 11-7085. After 3 weeks, we found that animals treated with DMSO exhibited massive bone destruction (Fig. 5Ai). Histological analysis revealed that tumor cells expanded within the entire marrow cavity, leading to extensive osteolytic bone lesions (Fig. 5B). In contrast, Bay 11-7085 inhibited intraosseous tumor growth (Fig. 5Aii). Histomorphometric assay indicated that this inhibitor decreased tumor burden as compared to the control (Fig. 5C).
Our in vitro experiments showed that Bay 11-7085 inactivated both NF-kB and AKT. Using IHC analysis, we found extensive nuclear staining of phosphorylated NF- $\mathrm{kB}$ p65 in tumor sections from control animals. In contrast, treatment with Bay 11-7085 markedly reduced the staining intensity in tumors (Fig. 5D). Notably, a large number of OS cells were positive for the nuclear staining of phosphorylated AKT in tumors from control mice, whereas the positively stained cells were hardly detected in tumors derived from Bay 11-7085-treated animals (Fig. 5E). These findings, in agreement with in vitro results, suggest that Bay 11-7085 represses tumor expansion in the bone by targeting both NF- $\mathrm{kB}$ and AKT, further supporting the crosstalk between these two pathways in the human OS. 
A
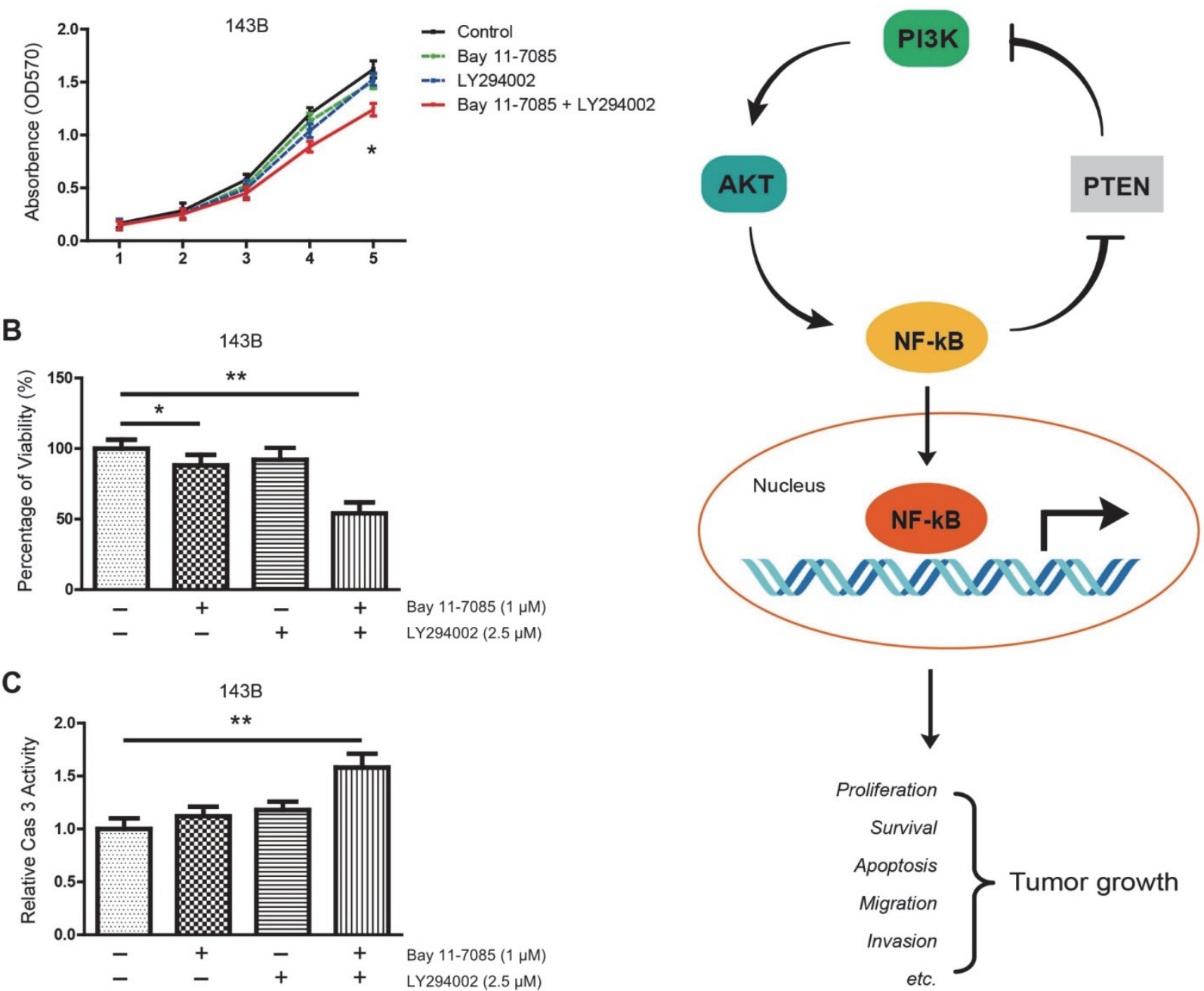

Fig. 6. Combined inhibitors targeting NF- $\mathrm{KB}$ and PI3K/AKT lead to an augmented antitumor effect. (A) MTT assay in tumor cells treated with Bay 11-7085 $(1 \mu \mathrm{M})$ and/or LY294002 $(2.5 \mu \mathrm{M}){ }^{*}$ denote $p$-value for the comparison between control and cocktail treatment groups. Tumor cells were also cultured in serum-starved medium and treated with Bay 11-7085 (1 $\mu \mathrm{M})$ and/or LY294002 (2.5 $\mu \mathrm{M})$ for $48 \mathrm{~h}$, followed by cell viability assay (B) and apoptosis assay (C). (D) A schematic outlining the crosstalk between NF- $\mathrm{KB}$ and PI3K/AKT pathways in OS.

${ }^{*} p<0.05,{ }^{* *} p<0.01$.

\section{Combined NF-KB and PI3K inhibitors induce an augmented antitumor effect}

Given that NF- $\kappa$ B impacted OS cell behavior in association with PI3K/AKT, we hypothesized that combined treatment with inhibitors simultaneously targeting NF- $\mathrm{BB}$ and PI3K/AKT would exert an additive or synergistic antitumor effect. To verify this hypothesis, we treated 143B and MG63 OS cells with a low dosage of Bay 11-7085 (1 $\mu \mathrm{M})$, PI3K inhibitor LY294002 (2.5 $\mu \mathrm{M})$, or a cocktail containing both inhibitors. MTT assay showed that Bay 11-7085 or LY294002 alone only minimally inhibited cell proliferation. However, the combination treatment significantly $(p=0.007)$ suppressed the proliferation rate (Fig. $6 \mathrm{~A})$. Similarly, Bay 11-7085 or LY294002 alone showed little effect in tumor cell viability, whereas cocktail treatment decreased viability (Fig. 6B). Further, Bay 11-7085 or LY294002 had no apparent effect in the induction of apoptosis but the combined administration of these two inhibitors induced pro-apoptotic activity (Fig. 6C). These data support that therapy using inhibitors targeting NF- $\mathrm{BB}$ and PI3K/AKT simultaneously induces an additive or synergistic antitumor effect in OS cells.

\section{Discussion}

NF- $\kappa$ B signaling plays a crucial role in diverse physiological and physiopathological processes. Hyperactivity of some oncogenic pathways, including Wnt/ $\beta$-catenin, PI3K/AKT, Notch, and MAPK are involved in human OS (Geryk-Hall and Hughes, 2009; Zhang et al., 2015). However, the role of NF- $\kappa$ B in OS development and progression has been poorly investigated. In our study, we reported that the phosphorylation levels of NF$\kappa \mathrm{B}$ p65 were higher in three OS cell lines than in normal osteoblasts. Notably, all tumor cells displayed an elevated endogenous NF- $\kappa \mathrm{B}$ reporter activity compared to that of osteoblasts. 
Therefore, our findings support the notion that activation of $\mathrm{NF}-\kappa \mathrm{B}$ occurs as a common event in the human OS, implying that this pathway may be critically implicated in osteosarcomagenesis. Interestingly, we observed that the phosphorylation of NF- $\kappa \mathrm{B}$ inhibitory protein I $\kappa \mathrm{B} \alpha$ was also upregulated in OS cells. This underscores that NF- $\mathrm{kB}$ is activated via the inhibition of IkBa.

In this study, treatment with NF- $\kappa B$ inhibitor Bay 11-7085 substantially reduced both basal level and TNFa-stimulated NF- $\kappa B$ reporter activity. This inhibitor also suppressed the expression of NF- $\kappa \mathrm{B}$ transcription target genes including BAFF, IL-6, IL-8, and TRAF-1 in OS cells. These results not only suggest that Bay 11-7085 inactivates NF- $\kappa B$-mediated transcriptional activity but also provide a clue that pharmacological inhibition of NF- $\mathrm{kB}$ may possess an antitumor effect.

Although previous studies have revealed a correlation between NF-kB and human OS (Gong et al., 2017; Iyer et al., 2016; Miwa et al., 2012), the mechanism whereby NF- $\kappa B$ impacts OS cell behavior is largely unknown. NF- $\kappa \mathrm{B}$ has been reported to stimulate the growth and motility in several types of human cancer cells (Kaltschmidt et al., 1999; Smith et al., 2014). In this study, we showed that Bay 11-7085 inhibited the proliferation and viability of OS cells, suggesting a growth-promoting effect of NF- $\kappa$ B. Of note, the effect of NF- $\kappa B$ in cancer cell apoptosis is controversial. NF- $\kappa B$ may exert either an anti- or pro-apoptotic activity in a cell type- and stimulus-dependent manner (Luo et al., 2005). Here, we found that Bay 11-7085 induced caspase 3 activity in OS cells, and this reflects that $\mathrm{NF}-\kappa \mathrm{B}$ possesses an anti-apoptotic activity. Migration and invasion are two crucial steps for cancer aggressiveness, such as metastasis (Bravo-Cordero et al., 2012; Tahtamouni et al., 2019). In our study, we reported that treatment with Bay 11-7085 impaired both migrative and invasive abilities. All these functional assays support the notion that NF- $\kappa \mathrm{B}$ is critically implicated in OS growth and aggressiveness. However, pharmacological inhibition of NF- $\kappa$ B may effectively suppress the oncogenic properties of OS.

It has been shown that many dysregulated pathways can interact with other pathways, thereby increasing the aggression of various human cancers (Prahallad and Bernards, 2016). NF-kB also cooperates with other pathways, including $\mathrm{PI}$ KK/AKT. In literature, NF- $\mathrm{KB}$ activity is modulated downstream of PI3K/AKT, leading to the formation of a PI3K/AKT/ $\mathrm{NF}-\kappa \mathrm{B}$ pathway nexus. For instance, tumorigenic mutations of PI3K can activate NF- $\kappa$ B in leukemia cells (Hutti et al., 2012). PI3K- and AKT-induced oncogenic transformation are also mediated via NF-kB-dependent transcription (Bai et al., 2009). In OS, CXCR4-inhibited apoptosis or MARK2-induced resistance to cisplatin chemotherapy is dependent on the activation of the PI3K/AKT/NF- $\kappa B$ axis (Jiang et al., 2018; Wei et al., 2020). Strikingly, we reported here that Bay 11-7085 dephosphorylated AKT in OS cells. This finding reveals that NF- $\kappa B$ also functions upstream of AKT. We further explored the mechanism of how NF- $\mathrm{BB}$ could activate AKT. Interestingly, we showed that treatment with Bay 11-7085 resulted in an induction of PTEN in OS cells. In light of PTEN that converts $\mathrm{PIP}_{3}$ to $\mathrm{PIP}_{2}$ and subsequently antagonizes PI3K/AKT activity, our results suggest an inverse relationship between NF- $\kappa B$ and PTEN, and also support that NF- $\kappa B$ activates AKT via its suppression of PTEN. Therefore, our data uncover the existence of a novel NF- $\mathrm{BB} / \mathrm{PTEN} / \mathrm{PI} \mathrm{KK} / \mathrm{AKT}$ axis in OS cells. In support of our findings, a recent clinicopathologic study has reported a negative correlation between NF- $\kappa \mathrm{B}$ and PTEN expression in human OS specimens (Gong et al., 2017). Vasudevan et al. (2004) also showed that NF- $\kappa$ B p65 could repress PTEN expression using a mechanism involving sequestration of limiting pools of transcriptional coactivators CBP/p300 in lung and thyroid cancers.

Based on our results and others, it seems likely that activation of NF- $\mathrm{BB}$ may occur upstream or downstream of PI3K/AKT, highlighting an NF- $\kappa$ B/PTEN/PI3K/AKT/NF- $\mathrm{B}$ loop in OS (Fig. 6D).

Importantly, using an orthotopic xenograft model, we reported that injection of OS cells induced extensive bone destruction in the tibia. In stark contrast, NF- $\mathrm{BB}$ inhibitor Bay 11-7085 substantially inhibited tumor progression in the bone. These findings reveal that NF- $\mathrm{BB}$ acts as a crucial regulator during intraosseous tumor growth. As we expected, the Bay 11-7085-mediated antitumor effect was correlated with its negative modulation of NF- $\kappa \mathrm{B}$, which was characterized by decreased expression of phosphorylated p65 subunit in tumor samples. Notably, this inhibitor also dramatically diminished the phosphorylation of AKT in tumor specimens. These in vivo results, in agreement with our in vitro data, support that Bay 11-7085 represses tumor growth in the bone by targeting $\mathrm{NF}-\kappa \mathrm{B}$ and $\mathrm{AKT}$, further confirming the interaction between these two pathways in OS.

Moreover, the findings that NF- $\mathrm{KB}$ interacted with $\mathrm{PI} 3 \mathrm{~K} / \mathrm{AKT}$ led to a rationale that concurrent treatment using inhibitors targeting the two oncogenic pathways might exert an enhanced antitumor effect. Interestingly, we found that treatment of OS cells with a low dosage of Bay 11-7085 or PI3K inhibitor LY294002 alone displayed little effect in tumor cell proliferation, viability, and apoptosis. In stark contrast, combined treatment with these two inhibitors efficiently decreased cell growth and survival. These results support that combination treatment using two inhibitors can induce an additive or synergistic antitumor effect. Consistent with our findings, Dumble et al. (2014) documented that combined therapy using the AKT inhibitor (GSK2141795) and the MEK inhibitor (trametinib) could result in an enhanced tumor-inhibiting effect in a mouse model of pancreatic cancer.

Aasen et al. (2019) also reported that combined inhibitors targeting MAPK and PI3K pathways would be more effective to increase apoptosis and inhibit tumor growth than monotherapy for the treatment of metastatic melanoma.

As such, based on our results, we propose that combination treatment using inhibitors targeting both $N F-\kappa B$ and PI3K/AKT pathways should be seriously considered as a promising therapeutic strategy to treat human OS.

Besides NF- $\mathrm{BB}$ hyperactivity in OS in our study, constitutive activation of NF- $\mathrm{KB}$ also occurs in a range of other human malignant diseases, such as multiple myeloma, acute/chronic myeloid leukemia, acute lymphocytic leukemia, as well as solid tumors, including prostate, breast, ovarian and colorectal cancer (Labbozzetta et al., 2020; Xia et al., 2014). Since $\mathrm{NF}-\kappa \mathrm{B}$ may upregulate genes involved in tumor cell proliferation, migration, invasion, anti-apoptosis, angiogenesis, and the development of resistance to chemotherapy, NF- $\kappa \mathrm{B}$ can function as a valid target for cancer treatment. So far, targeting $\mathrm{NF}-\kappa \mathrm{B}$ as an antitumor therapy using natural compounds or selective inhibitors has been tested in several clinical trials with proven effectiveness in patients suffering from leukemia, lymphoma, as well as multiple myeloma (Labbozzetta et al., 2020; Xia et al., 2014). Interestingly, garcinol (an active component of Garcinia indica) has been reported to suppress the constitutive activation of NF- $\mathrm{NB}$ in head and neck squamous cell carcinoma (HNSCC) and result in an inhibition of tumor growth both in vitro and in vivo (Li et al., 2013). Piva et al. (2009) reported that crude extracts of Emblica officinalis induced apoptosis of mature osteoclasts via its inhibition of NF- $\kappa$ B. 
As osteoclast hyperactivity plays a crucial role in OS tumorigenesis, whether Emblica officinalis helps to inhibit tumor-associated osteoclastogenesis thereby blocking OS expansion merits investigation.

The importance of our study is not only the identification of NF- $\kappa B$ hyperactivity in OS cells, but also the discovery that pharmacological inhibition of NF- $\mathrm{BB}$ could efficiently block tumor growth and aggressiveness both in vitro and in vivo. We also uncovered the existence of crosstalk between NF- $\mathrm{B}$ and PTEN/PI3K/AKT in OS cells and more strikingly, combined treatment using inhibitors targeting both NF- $\kappa \mathrm{B}$ and PI3K/AKT efficiently triggered an augmented antitumor effect. Hence, our results strongly support that targeting $\mathrm{NF}-\kappa \mathrm{B}$ should be considered as a valid molecular therapy for this bone cancer. Also, our study proposes that targeting multiple pathways simultaneously using sub-toxic doses of specific inhibitors may enhance the response to therapy and also reduces the chances of toxicity.

\section{Conclusions}

In general, we show here for the first time that NF- $\kappa \mathrm{B}$ activation is a common event in the human OS that potentiates tumor growth and aggressiveness. Pharmacological inhibition of NF- $\kappa$ B inhibits the oncogenic phenotype of OS cells through its inactivation of both NF- $\mathrm{KB}$ and PI3K/AKT pathways. Combined treatment using inhibitors targeting both pathways can exert an augmented antitumor effect, which should be considered as a promising therapeutic strategy to treat human OS.

\section{Conflict of interests}

There is no competing interest related to the manuscript.

\section{Acknowledgement}

This study was supported by the Shandong Provincial Medical Technology \& Development Program (2019WS459) to J.D.

\section{Ethics approval}

The animal study was approved by the Animal Care Committee of Shandong Provincial Hospital.

\section{References}

Aasen SN, Parajuli H, Hoang T, Feng Z, Stokke K, Wang J, et al. (2019). Effective Treatment of Metastatic Melanoma by Combining MAPK and PI3K Signaling Pathway Inhibitors. Int J Mol Sci 20(17): 4235. DOI: 10.3390/ijms20174235.

Bai D, Ueno L, Vogt PK (2009). Akt-mediated regulation of NFkappaB and the essentialness of NFkappaB for the oncogenicity of PI3K and Akt. Int J Cancer 125: 2863-2870. DOI: 10.1002/ ijc. 24748 .

Bravo-Cordero JJ, Hodgson L, Condeelis J (2012). Directed cell invasion and migration during metastasis. Curr Opin Cell Biol 24: 277-283. DOI: 10.1016/j.ceb.2011.12.004.

Dumble M, Crouthamel MC, Zhang SY, Schaber M, Levy D, Robell K, et al. (2014). Discovery of novel AKT inhibitors with enhanced anti-tumor effects in combination with the MEK inhibitor. PLoS One 9: e100880. DOI: 10.1371/journal.pone.0100880.

Fishman P, Bar-Yehuda S, Madi L, Rath-Wolfson L, Ochaion A, Cohen S, Baharav E (2006). The PI3K-NF-kappaB signal transduction pathway is involved in mediating the antiinflammatory effect of IB-MECA in adjuvant-induced arthritis. Arthritis Res Ther 8: R33. DOI: 10.1186/ar1887.
Georgescu MM (2010). PTEN Tumor Suppressor Network in PI3K-Akt Pathway Control. Genes Cancer 1: 1170-1177. DOI: $10.1177 / 1947601911407325$.

Geryk-Hall M, Hughes DP (2009). Critical signaling pathways in bone sarcoma: candidates for therapeutic interventions. Curr Oncol Rep 11: 446-453. DOI: 10.1007/s11912-009-0061-z.

Ghoneum A, Said N (2019). PI3K-AKT-mTOR and NFkappaB Pathways in Ovarian Cancer: Implications for Targeted Therapeutics. Cancers (Basel) 11(7): 949. DOI: 10.3390/ cancers11070949.

Gong T, Su X, Xia Q, Wang J, Kan S (2017). Expression of NF-kappaB and PTEN in osteosarcoma and its clinical significance. Oncol Lett 14: 6744-6748. DOI: 10.3892/ol.2017.6972.

Gorlick R, Maris JM, Houghton PJ, Lock R, Carol H, Kurmasheva RT, et al. (2012). Testing of the Akt/PKB inhibitor MK-2206 by the Pediatric Preclinical Testing Program. Pediatr Blood Cancer 59: 518-524. DOI: $10.1002 / \mathrm{pbc} .23412$.

Hayden MS, Ghosh S (2014). Regulation of NF-kappaB by TNF family cytokines. Semin Immunol 26: 253-266. DOI: 10.1016/j. smim.2014.05.004.

Hutti JE, Pfefferle AD, Russell SC, Sircar M, Perou CM, Baldwin AS (2012). Oncogenic PI3K mutations lead to NF-kappaB-dependent cytokine expression following growth factor deprivation. Cancer Res 72: 3260-3269. DOI: 10.1158/0008-5472.CAN-11-4141.

Israel A (2010). The IKK complex, a central regulator of NF-kappaB activation. Cold Spring Harb Perspect Biol 2: a000158. DOI: 10.1101/cshperspect.a000158.

Iyer SV, Ranjan A, Elias HK, Parrales A, Sasaki H, Roy BC, et al. (2016). Genome-wide RNAi screening identifies TMIGD3 isoform 1 as a suppressor of NF-kappaB and osteosarcoma progression. Nat Commun 7: 13561. DOI: 10.1038/ncomms13561.

Jiang C, Ma S, Hu R, Wang X, Li M, Tian F, et al. (2018). Effect of CXCR4 on Apoptosis in Osteosarcoma Cells via the PI3K/Akt/NFkappabeta Signaling Pathway. Cell Physiol Biochem 46: 22502260. DOI: $10.1159 / 000489593$.

Jin Y, Liu L, Chen B, Bai Y, Zhang F, Li Q, et al. (2017). Involvement of the PI3K/Akt/NF-kappaB Signaling Pathway in the Attenuation of Severe Acute Pancreatitis-Associated Acute Lung Injury by Sedum sarmentosum Bunge Extract. Biomed Res Int 2017: 9698410. DOI: 10.1155/2017/9698410.

Kaltschmidt B, Kaltschmidt C, Hehner SP, Droge W, Schmitz ML (1999). Repression of NF-kappaB impairs HeLa cell proliferation by functional interference with cell cycle checkpoint regulators. Oncogene 18: 3213-3225. DOI: 10.1038/sj.onc.1202657.

Kunnumakkara AB, Shabnam B, Girisa S, Harsha C, Banik K, Devi TB, et al. (2020). Inflammation, NF-kappaB, and Chronic Diseases: How are They Linked? Crit Rev Immunol 40: 1-39. DOI: 10.1615/ CritRevImmunol.2020033210.

Kushlinskii NE, Fridman MV, Braga EA (2016). Molecular Mechanisms and microRNAs in Osteosarcoma Pathogenesis. Biochemistry (Mosc) 81: 315-328. DOI: 10.1134/ S0006297916040027.

Labbozzetta M, Notarbartolo M, Poma P (2020). Can NF-kappaB Be Considered a Valid Drug Target in Neoplastic Diseases? Our Point of View. Int J Mol Sci 21: 3070. DOI: 10.3390/ijms21093070.

Li B, Cheung PY, Wang X, Tsao SW, Ling MT, Wong YC, Cheung AL (2007). Id-1 activation of PI3K/Akt/NFkappaB signaling pathway and its significance in promoting survival of esophageal cancer cells. Carcinogenesis 28: 2313-2320. DOI: 10.1093/carcin/ bgm152.

Li F, Shanmugam MK, Chen L, Chatterjee S, Basha J, Kumar AP, Kundu TK, Sethi G (2013). Garcinol, a polyisoprenylated benzophenone modulates multiple proinflammatory signaling cascades leading to the suppression of growth and survival of head and neck carcinoma. Cancer Prev Res (Phila) 6: 843-854. DOI: 10.1158/1940-6207.CAPR-13-0070.

Liang CC, Park AY, Guan JL (2007). In vitro scratch assay: a convenient and inexpensive method for analysis of cell migration in vitro. Nat Protoc 2: 329-333. DOI: 10.1038/nprot.2007.30.

Liao D, Zhong L, Duan T, Zhang RH, Wang X, Wang G, et al. (2015). Aspirin Suppresses the Growth and Metastasis of Osteosarcoma through the NF-kappaB Pathway. Clin Cancer Res 21: 5349-5359. DOI: 10.1158/1078-0432.CCR-15-0198. 
Liu W, Jiang D, Gong F, Huang Y, Luo Y, Rong Y, et al. (2020). miR210-5p promotes epithelial-mesenchymal transition by inhibiting PIK3R5 thereby activating oncogenic autophagy in osteosarcoma cells. Cell Death Dis 11: 93. DOI: 10.1038/s41419-020-2270-1.

Luo JL, Kamata H, Karin M (2005). IKK/NF-kappaB signaling: balancing life and death - a new approach to cancer therapy. J Clin Invest 115: 2625-2632. DOI: 10.1172/JCI26322.

Miwa S, Sugimoto N, Yamamoto N, Shirai T, Nishida H, Hayashi K, et al. (2012). Caffeine induces apoptosis of osteosarcoma cells by inhibiting AKT/mTOR/S6K, NF-kappaB and MAPK pathways. Anticancer Res 32: 3643-3649. DOI: 10.3892/ijo.2011.1051.

Oeckinghaus A, Ghosh S (2009). The NF-kappaB family of transcription factors and its regulation. Cold Spring Harb Perspect Biol 1: a000034. DOI: 10.1101/cshperspect.a000034.

Papa A, Pandolfi PP (2019). The PTEN(-)PI3K Axis in Cancer. Biomolecules 9(4): 153. DOI: 10.3390/biom9040153.

Piva R, Penolazzi L, Borgatti M, Lampronti I, Lambertini E, Torreggiani E, Gambari R (2009). Apoptosis of human primary osteoclasts treated with molecules targeting nuclear factorkappaB. Ann N Y Acad Sci 1171: 448-456. DOI: 10.1111/j.17496632.2009.04906.x.

Polivka J, Jr., Janku F (2014). Molecular targets for cancer therapy in the PI3K/AKT/mTOR pathway. Pharmacol Ther 142: 164-175. DOI: 10.1016/j.pharmthera.2013.12.004.

Prahallad A, Bernards R (2016). Opportunities and challenges provided by crosstalk between signalling pathways in cancer. Oncogene 35: 1073-1079. DOI: 10.1038/onc.2015.151.

Puar YR, Shanmugam MK, Fan L, Arfuso F, Sethi G, Tergaonkar V (2018). Evidence for the Involvement of the Master Transcription Factor NF-kappaB in Cancer Initiation and Progression. Biomedicines 6(3): 82. DOI: 10.3390/biomedicines6030082.

Ritch SJ, Brandhagen BN, Goyeneche AA, Telleria CM (2019). Advanced assessment of migration and invasion of cancer cells in response to mifepristone therapy using double fluorescence cytochemical labeling. BMC Cancer 19: 376. DOI: 10.1186/ s12885-019-5587-3.

Smith SM, Lyu YL, Cai L (2014). NF-kappaB affects proliferation and invasiveness of breast cancer cells by regulating CD44 expression. PLoS One 9: e106966. DOI: 10.1371/journal.pone.0106966.

Tahtamouni L, Ahram M, Koblinski J, Rolfo C (2019). Molecular Regulation of Cancer Cell Migration, Invasion, and Metastasis. Anal Cell Pathol (Amst) 2019: 1356508. DOI: 10.1155/2019/1356508.

Tang QL, Xie XB, Wang J, Chen Q, Han AJ, Zou CY, et al. (2012). Glycogen synthase kinase-3beta, NF-kappaB signaling, and tumorigenesis of human osteosarcoma. J Natl Cancer Inst 104: 749-763. DOI: 10.1093/jnci/djs210.

Vallabhapurapu S, Karin M (2009). Regulation and function of NF-kappaB transcription factors in the immune system. Annu Rev Immunol 27: 693-733. DOI: 10.1146/annurev. immunol.021908.132641.

Vasudevan KM, Gurumurthy S, Rangnekar VM (2004). Suppression of PTEN expression by NF-kappa B prevents apoptosis. Mol Cell Biol 24: 1007-1021. DOI: 10.1128/MCB.24.3.1007-1021.2004.

Wei X, Xu L, Jeddo SF, Li K, Li X, Li J (2020). MARK2 enhances cisplatin resistance via PI3K/AKT/NF-kappaB signaling pathway in osteosarcoma cells. Am J Transl Res 12: 1807-1823.

Xi Y, Chen Y (2017). PTEN Plays Dual Roles As a Tumor Suppressor in Osteosarcoma Cells. J Cell Biochem 118: 2684-2692. DOI: $10.1002 / j c b .25888$.

Xia Y, Shen S, Verma IM (2014). NF-kappaB, an active player in human cancers. Cancer Immunol Res 2: 823-830. DOI: 10.1158/2326-6066.CIR-14-0112.

Zhang J, Yu XH, Yan YG, Wang C, Wang WJ (2015). PI3K/Akt signaling in osteosarcoma. Clin Chim Acta 444: 182-192. DOI: 10.1016/j.cca.2014.12.041. 